\title{
Erratum to: Two cobalt(II) metal-organic frameworks based on mixed 1,2,4,5-benzenetetracarboxylic acid and bis(benzimidazole) ligands
}

\author{
Jin Ming Hao $\cdot$ Yue Hua Li • Huan Huan Li • \\ Guang Hua Cui
}

Published online: 29 October 2013

(C) Springer Science+Business Media Dordrecht 2013

\section{Erratum to: Transition Met Chem}

\section{DOI 10.1007/s11243-013-9760-2}

In the first sentence of the Abstract, "bis(5,6-dimethylbenzimidazole)" should be "bis(benzimidazole)" and "1,4-bis(5,6-dimethylbenzimidazole-1-ylmethyl)benzene" should be "1,4-bis(benzimidazole-1-ylmethyl)benzene".

In the first sentence of the third paragraph of the Introduction, "bis(5,6-dimethylbenzimidazole-1-ylmethyl)benzene" should be "bis(benzimidazole-1-ylmethyl)benzene".

In the section Experimental, in the first sentence below Synthesis of complex 1 " $0.40 \mathrm{~g}$ " should be " $0.34 \mathrm{~g}$ ".

In the section Experimental, in the second sentence below Synthesis of complex $\mathbf{1}$ " $F_{\mathrm{w}}=901.19$ " should be " $F_{\mathrm{w}}=901.17 "$.
In Table 1, the first entry in the column 1 should be " $\mathrm{C}_{43} \mathrm{H}_{36} \mathrm{Co}_{1.50} \mathrm{~N}_{6} \mathrm{O}_{11}$ ".

In Scheme 1, L1 should look like this:

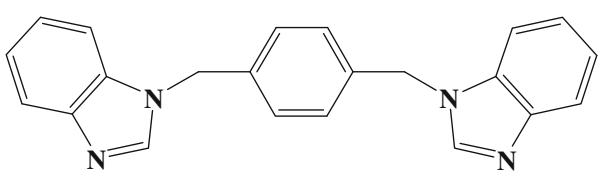

ligand L1

The online version of the original article can be found under doi:10. 1007/s11243-013-9760-2.

J. M. Hao · Y. H. Li · H. H. Li · G. H. Cui $(\bowtie)$

College of Chemical Engineering, Hebei United University,

46 West Xinhua Road, Tangshan 063009, Hebei,

People's Republic of China

e-mail: tscghua@126.com 